Revista Complutense de Educación

ISSNe: 1988-2793

http://dx.doi.org/10.5209/RCED.53431

\title{
La tutoría en el escenario universitario actual
}

Autor: Ernesto López Gómez

Editorial: Aracne Editrice

Año de publicación: 2016

$N^{a}$ de páginas: 180

ISBN: 978-88-548-8512-7

En esta reseña se ofrece una breve presentación del libro "La tutoría en el escenario universitario actual". Su autor, Ernesto López Gómez, es investigador posdoctoral en la Universidad Nacional de Educación a Distancia (UNED, España). Del título se evidencia la temática y el contexto en el que se aborda. De este modo, el lector encontrará en las páginas de este libro el tratamiento de un tema clásico y a la vez novedoso en la universidad, como es la tutoría. En efecto, la tutoría es una línea de investigación abundantemente explorada, tanto en etapas preuniversitarias como en la universidad.

Así, la tutoría universitaria ha sido objeto de estudios amplios y reflexiones rigurosas en los más diversos contextos universitarios, si bien, con la actualidad del sentido universitario en el EEES, viene siendo un tópico recurrente en investigación educativa durante la última década. La investigación ha mostrado modelos, enfoques, programas, perspectivas y prácticas tutoriales en el contexto universitario, avaladas por muy diversos proyectos de investigación.

A lo largo de las páginas de esta obra se ofrecen argumentos y reflexiones fundamentadas en un extenso apoyo documental, fundamentalmente desde un punto de vista conceptual, aunque con una gran proyección aplicada. Su estructura se concreta en tres grandes bloques que encuentran continuidad y coherencia entre sí.

El primero de ellos bajo el título La actualidad de la Universidad Europea, refiere a un estudio sobre la idea de universidad desde el presente, presentando los modelos fundamentales para comprender su historia. Se describe y analiza la anatomía propia del modelo universitario del EEES, desde el marco legislativo y normativo que ha acompañado el proceso de armonización de la educación superior europea. Finalmente, en esta parte inicial, se discuten sus elementos sustantivos, identificando como tales: formación por competencias, preparación de profesionales y empleabilidad; investigación, especialización, internacionalización y movilidad; ciudadanía europea, dimensión social de la educación universitaria; competitividad y aseguramiento de la calidad.

En el segundo bloque titulado, El Profesorado Universitario: Perfiles, Tipología y Competencias, López Gómez aborda como objeto de estudio al profesorado universitario, destacando su diversidad de perfiles y tipología así como esbozando sus 
competencias más características en el actual escenario universitario. De entre todas ellas destacan, además del dominio del contenido, la planificación de la enseñanza, el diseño didáctico, la comunicación y presentación del discurso, el manejo de herramientas y recursos tecnológicos, el feedback y la evaluación formativa así como la tutoría. Todas ellas relevantes para el adecuado desarrollo de la docencia. Si bien, por el interés y enfoque de este trabajo y su compromiso con la labor tutorial, el tema se va acotando en este segundo bloque temático, al identificar y caracterizar al profesorado universitario como agente relevante de la tutoría universitaria desde una perspectiva formativa y orientadora.

Así, en el tercer bloque titulado Hacia un Modelo de Tutoría Universitaria Integral (MOTUI) adaptado al EEES, el autor asume el carácter sustantivo y nuclear de esta obra, ofreciendo un modelo en el que aborda, en primer término, el sentido de la tutoría integral en la universidad, presentando su concepto y finalidades; así como desarrollando las dimensiones sustantivas a atender por la tutoría para que ésta sea denominada integral en el contexto universitario, a saber: personal - social, académica y profesional. Además, se tienen en cuenta las coordenadas espacio y tiempo, proponiendo momentos claves para la orientación universitaria desde que el estudiante comienza su periodo universitario, durante el mismo y el periodo crítico de transición al mercado laboral y al escenario social tras culminar su formación universitaria. Finalmente, se proponen los indicadores que permiten dar sentido y concretar las citadas dimensiones, tras un proceso de validación llevado a cabo.

Para ir terminando, destacamos la profunda y extensa revisión bibliográfica realizada por López Gómez para la elaboración de esta obra, que sin duda se constituye en libro de referencia, no solo en el ámbito estrictamente universitario, también para la educación secundaria, dada las posibilidades de transferencia de algunas ideas del texto a otras etapas del sistema educativo.

Como señala el propio autor, es una obra que a permitirá “...seguir pensando sobre una realidad formativa que vincula a estudiantes y profesorado (...) y poder avanzar en nuevas propuestas prácticas, operativas y concretas" que hagan posible hacer operativo la propuesta conceptual presentad.

Adiela Ruiz Cabezas

Universidad Nacional de Educación a Distancia adiruiz@madrid.uned.es 